\title{
Vitamin D may protect against multiple organ damage caused by COVID-19
}

\author{
Aygun $\mathrm{H}$ \\ Department of Physiology, Faculty of Medicine, Tokat Gaziosmanpasa University, Tokat, Turkey. \\ hatice_5aygun@hotmail.com
}

\begin{abstract}
The novel coronavirus COVID-19 outbreak quickly spread across many countries and has become a worldwide threat to health, trade and travel. In terms of clinical manifestations, although it starts as an acute respiratory disorder, it could eventually lead to death by causing damage to many organs such as: lung, liver, kidney and heart. It has been shown that COVID-19 pathology is mediated by an excessive inflammation, oxidation and an aggravated immune response. Vitamin $\mathrm{D}$ is a an immunomodulator hormone and has receptors in many tissues and organs. In many studies, vitamin D was shown to have antimicrobial and antiinflammatory properties. In addition, since COVID-19 infection causes a cytokine storm, vitamin D can have a protective effect on many tissues and organs by reducing the production of proinflammatory cytokines. Vitamin $D$ has a high safety profile, and thus could be beneficial against multiple organ damage in COVID-19 patients. This paper aims to highlight the potential benefits of vitamin D against multiple organ damage caused by COVID-19 (Fig. 1, Ref. 109). Text in PDF www.elis.sk KEY WORDS: COVID-19, cytokine, inflammation, vitamin D.
\end{abstract}

\section{Introduction}

Pneumonia outbreak caused by the novel coronavirus (COVID-19), which was firstly reported in Wuhan town in the Chinese State of Hubei, spread rapidly all over China, and despite the efforts to prevent its spread, virus has now reached a pandemic level around the world $(1,2,3)$. This virus is transmitted by droplets, close contact and other means, and patients in the incubation period can potentially infect other people (4). Mild cases of COVID-19 cause symptoms of fatigue, fever, vomit, diarrhoea and dry cough. In severe cases, on the other hand, hypoxemia and respiratory distress develop about seven days after the start of the infection, followed by an acute respiratory distress syndrome (ARDS), septic shock, metabolic acidosis, and even death $(5,6)$. In the study, in which 1099 laboratory-confirmed cases were examined, common manifestation included fever (88.7\%), cough (67.8\%), sputum production (33.4\%), fatigue (38.1\%), shortness of breath (18.6\%), headache $(13.6 \%)$, sore throat $(13.9 \%)$, diarrhoea (3.8\%), and vomiting $(5.0 \%)(2)$.

Coronaviruses infect humans and other vertebrates. Novel COVID-19 is a coronavirus and is closely related to the viruses responsible for Severe Acute Respiratory Syndrome (SARS-CoV)

Department of Physiology, Faculty of Medicine, Tokat Gaziosmanpasa University, Tokat, Turkey

Address for correspondence: H. Aygun, Dr, Department of Physiology, Faculty of Medicine, Tokat Gaziosmanpasa University, 60030 Tokat, Turkey.

Phone: +905399631308 in 2003 and Middle East Respiratory Syndrome (MERS-CoV) in 2012, which generated severe pneumonia symptoms. These three viruses can lead to intestinal, neuronal, hepatic and respiratory diseases, and may cause the multiple organ failure, ARDS, and in severe cases even death $(7,8,9)$. A small-scale autopsy study on heart, lung, spleen, liver, kidney, bone marrow, stomach, pancreas, intestine, skin and thyroid performed in three patients, who died of the novel coronavirus-related pneumonia in Chongqing, China revealed significant pathological lesions in the lungs of the patients including alveolar exudative inflammation, alveolar epithelial proliferation, interstitial inflammation and hyaline membrane formation (10). It was reported in the same study that although 2019-nCoV was mainly located in the lung, infectionrelated damage was also observed in blood vessels, heart, kidneys, liver and other organs. Huang et al (6) reported that about $20 \%$ of the 41 cases had diabetes, while Chen et al (11) reported that about $40 \%$ of 99 cases had cardio-cerebrovascular disease. Li et al (12), on the other hand, studied 1.527 novel COVID-19 cases, and reported that $17.1 \%$ of the patients had hypertension, $16.4 \%$ cardio-cerebrovascular disease, $9.7 \%$ diabetes and at least $8.0 \%$ an acute cardiac injury. In another study conducted in China with over 40,000 confirmed COVID-19 cases, fatality rate was $2.3 \%$, and old age $>70$ years $(10.2 \%)$, diabetes $(7.3 \%)$, cardiovascular disease $(10.5 \%)$, and hypertension $(6.0 \%)$ were the most frequently reported co-morbidities (13). The incidence of liver injury was reported (14) in deaths associated with COVID-19. The recent reports pointed to a high degree of inflammation in patients diagnosed with COVID-19. Indeed, multiple organ failure and deaths were reported to be caused by a widespread inflammation. 
Vitamin D is a fat-soluble vitamin, and it is either taken in diet or synthesized in the skin by exposure to solar ultraviolet B radiation. Vitamin D is inactive, and it is metabolized twice: first in the liver and then in the kidney by cytochrome $\mathrm{P} 450$ enzymes to the active form 1,25 dihydroxyvitamin $\mathrm{D}(1,25(\mathrm{OH}) 2 \mathrm{D}(15)$. It plays a crucial role in phosphorous and calcium homeostasis (16). Besides, it is an immunomodulatory hormone and steroid, and regulates body's immune response (17). A high prevalence of vitamin D deficiency was demonstrated in critical diseases involving an acute respiratory failure, acute kidney failure, increased rates of infection, cardiovascular disease, sepsis $(18,19,20,21$, 22). Beneficial effects of vitamin $D$ supplements on blood glucose and lipid levels, body fat mass and blood pressure were reported in most studies (23). In addition, Chang and Lee (24) mentioned vitamin D deficiency as a risk factor for chronic liver and renal diseases, hyperparathyroidism, growth hormone deficiency and diabetes mellitus. Similarly, Hu et al (25) suggested that low levels of the serum $25(\mathrm{OH}) \mathrm{D}$ was indicative of the type 2 diabetes risk.

The use of approved drugs with anti-inflammatory properties and with a proven safety profiles could be useful in preventing the hyperinflammation and decreasing the mortalities caused by COVID-19.

\section{COVID-19 and inflammatory cytokine storm}

ACE2 is a homologue of angiotensin converting enzyme (ACE) with a $40 \%$ identity and $61 \%$ similarity (26). ACE2 is involved in the formation of angiotensin-(1-7) and angiotensin-(1-9) from angiotensin II and angiotensin I, respectively (27, 28). $\mathrm{CoV}$ and 2019-nCoV are known to use ACE2 as a receptor for entering the cell. ACE2 is abundantly expressed in the type II alveolar cells (AT2) in the lung $(14,29,30)$, endothelial cells in liver (31), upper and stratified epithelial cells in oesophagus, absorptive enterocytes in ileum and colon (32), kidney proximal tubule cells, myocardial cells and bladder urothelial cells (29) and cholangiocytes (33). These tissues and organs are potential targets for 2019-nCoV. The recent study showed that ACE2 is abundantly expressed in mouth and tongue, facilitating the viral entrance into the host (34).

In order to enter the target cells, 2019-nCoV first should tightly bind to ACE2. Transmembrane protease serine 2 (TMPRSS2) is vital for spike glycoprotein in coronaviruses priming after binding to ACE2 $(35,36,37)$. The virus damages the cell by copying itself inside the cell.

Recent studies showed that 2019-nCoV virus triggered a Thelper 1 (Th1) type cytokine response upon the infection of macrophages. Patients infected with 2019-nCoV could have plasma cytokines and chemokines such as: interleukin (IL)-1, IL-1B, IL-2, IL-6, IL-7, IL-8, IL-10, IL-12, IL-13, IL-17, granulocyte colony stimulating factor (GCSF), interferon- $\gamma$ inducible protein 10 (IP-10), monocyte chemoattractant protein 1 (MCP-1), fibroblast growth factor (FGF), macrophage inflammatory protein 1- $\alpha$ (MIP- $1 \alpha)$, and tumour necrosis factor- $\alpha$ (TNF- $\alpha)$, hepatocyte growth factor (HGF), platelet-derived growth factor (PDGF), vascular endothelial growth factor (VEGF), tumour necrosis fac- tor (TNF $\alpha$ ), and gamma interferon (IFN- $\gamma),(6,38,39,40)$. Both IL-1B and TNF $\alpha$ promote TH17 responses and increase vascular permeability and leakage (41). The clinical trial with IL-6 receptor blocker tocilizumab has been approved in China for the COVID-19 patients, who developed pneumonia and had elevated IL-6 (ChiCTR2000029765). Chloroquine is a drug with immunomodulator effects suppressing production/release of the TNFa and IL- 6 and has long been used for the treatment of malaria $(42,43)$. Recently, Wang et al (44) reported that chloroquine is eminently effective in the control of 2019-nCoV infection under in vitro conditions. Clinical data collected so far revealed that inflammation is the major characteristic of COVID-19 patients. It was shown in many studies that the cytokine storm activated by an excessive inflammation contributes considerably to the pathogenesis of COVID-19. Thus, drugs that are effective in reducing inflammation appear to be beneficial.

\section{Vitamin D and inflammatory cytokine storm}

Preventing hyperinflammation caused by COVID-19 using approved drugs with anti-inflammatory effects and proven safety profiles could be useful to reduce the mortality. Activation of vitamin D receptors (VDRs) needs 1,25(OH)D3, the active form of vitamin D. Almost every organ and system of the body including immune cells have vitamin D receptor. VDRs are found in many different cell types such as: gonad, pancreas, kidney, liver, heart, lung, brain, breast cells, hematopoietic cells, and macrophages, monocytes and dendritic cells of the immune system. The activation of VDR affects both innate and adaptive immunity (45). Vitamin D is a direct and indirect modulator of Th1 cells. The production of Th1 cells is suppressed by vitamin D $(46,47,48)$. Additionally, vitamin D can decrease the production of inflammatory cytokines such as: IL-6, IL-8, IL-12 and IL-17, and thus prevent inflammation from progressing and damaging to other organs $(49,50,51)$. Vitamin D also reduces the production of TNF $\alpha$ and NFKB $(52,53)$. Moreover, 1,25(OH)2D directly inhibits IFN- $\gamma$ and IL-2 $(54,55)$. Vitamin D could diminish cytokine storm caused by COVID-19 and could exert protective effects against multiple organ damage.

\section{Association of Vitamin D with COVID-19 and renin angio- tensin system}

The renin angiotensin system (RAS) is of critical role in the regulation of volume, electrolyte homeostasis and blood pressure. ACE2 is the crucial counter-regulator of the RAS. ACE2 hydrolyses angiotensin II (Ang II) into Ang-(1-7) and reduces its level. Angiotensin II, the final product of RAS, is a powerful vasoconstrictor. It could lead to systemic vasoconstriction and promotes the release of aldosterone and regulates the blood pressure (56).

As in COVID-19, ACE2 is the potential receptor for SARSCoV virus to enter the cell, and the main cause of deaths is the progression of pneumonia to ARDS, which is an acute severe lung failure (57). ACE2 expression in lungs was shown to be significantly down-regulated in the wild type mice infected with the SARS$\mathrm{CoV}$ (58). In a similar way, in vivo intraperitoneal administration 


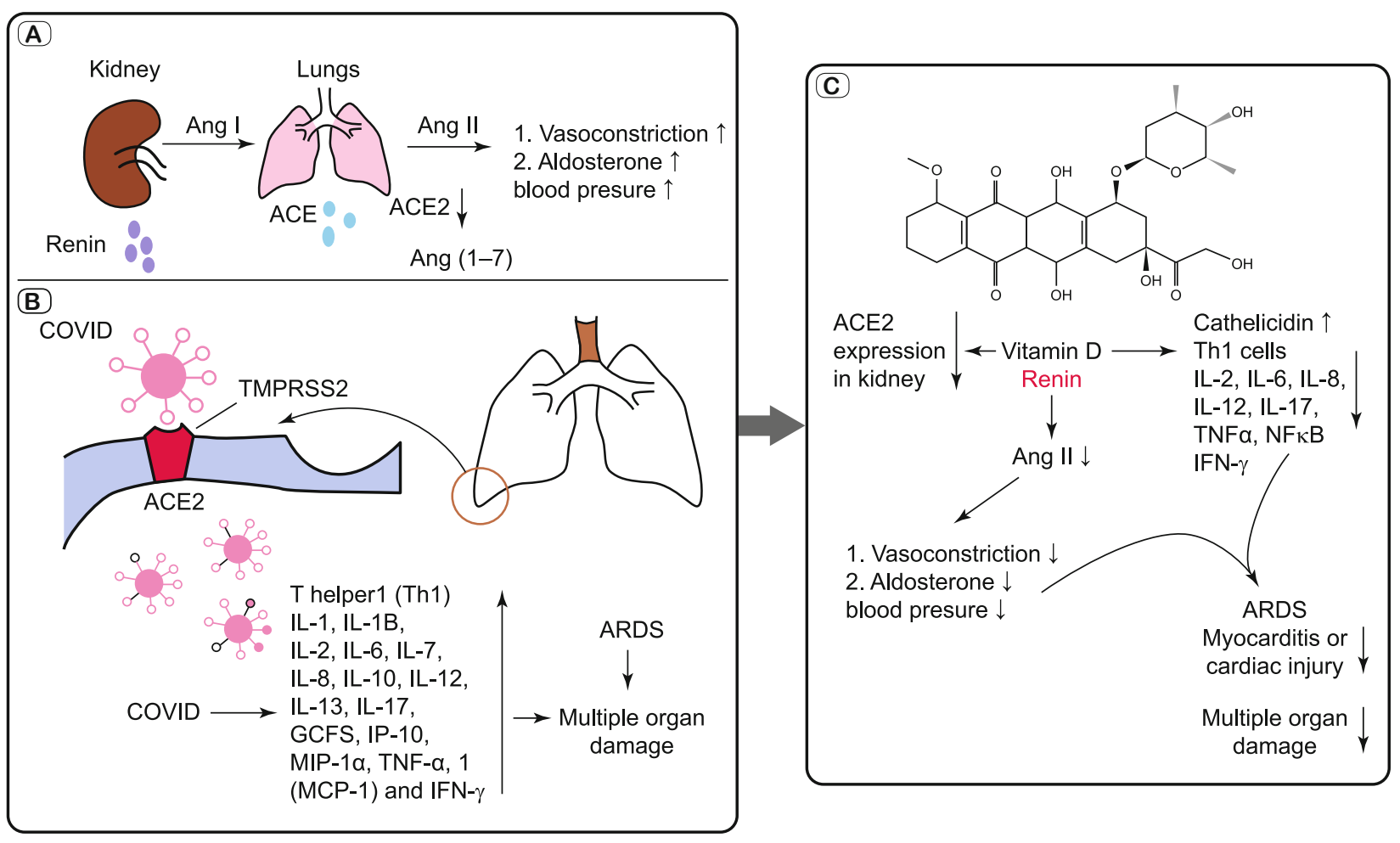

Fig. 1. A) Physiological function of RAS and the task of ace2 enzyme in the lung. B) The COVID-19 virus binds to the ACE2 receptor in the lungs. TMPRSS2 enters the cell thanks to the serine protease enzyme and replicates itself. Then, a cytokine storm occurs, resulting in ARDS and multiple organ damage. C) Vitamin D suppresses the release of cytokines, preventing a cytokine storm caused by COVID-19. It exerts an antimicrobial effect by increasing the release of cathelicidin. Vitamin D prevents Ang II accumulation by suppressing renin release. Thus, ARDS development and multiple organ damage could be avoided. Vitamin D also reduces ACE2 expression in the kidney and provides a protective effect against COVID-19 infection in patients with diabetes and acute renal failure.

of recombinant SARS-spike protein to wild type mice or in vitro application of Vero E6 cells were reported to downregulate ACE2 expression. Similarly, Ang II peptide levels were increased and ARDS improved in mice injected with recombinant SARS-spike protein. Pharmacological inhibition of Ang II and partial remediation of ARDS symptoms were shown $(58,59)$. This finding indicates that a negative control of the level of Ang II by ACE2 has an important role in ARDS pathogenesis.

In COVID-19 infection, the virus binds to ACE2 receptors to enter the cell, and ACE2 cannot perform its physiological function. Thus, COVID-19 infection may downregulate ACE2, causing a toxic overaccumulation of Ang II $(60,61)$. Accumulated Ang II causes a pulmonary vasoconstriction through AT1 receptors and develops pulmonary oedema by increasing the pulmonary vascular permeability (62). In addition, elevated Ang II level triggers oxidative stress, causing the development of inflammation and fibrosis (60). This condition can lead to the occurrence of ARDS, which is the most severe form of the lung injury. It often induces multiple organ damage.

Vitamin D is also a negative endocrine regulator of the renin release. In many studies, vitamin D and analogues were shown to directly inhibit the renin biosynthesis $(63,64,65)$. The study reported that vitamin D receptor-lacking mice had elevated levels of renin and Ang II (63). The experimental diabetes model created by STZ, vitamin D supplementation was demonstrated to suppress the renin and Ang II levels (66). Vitamin D supplementation was shown to protect against lipopolysaccharide-induced acute lung injury by inhibiting the expression of renin, ACE and Ang II (67). Vitamin D can interfere with Ang II accumulation by suppressing the release of renin in patients infected with COVID-19, thereby preventing ARDS development and multiple organ damage.

\section{Vitamin D and lung diseases}

Many patients with COVID-19 develop ARDS, which could eventually lead to pulmonary oedema, lung failure, heart, liver and kidney damage. These outcomes are associated with the cytokine storm, manifested with elevated serum levels of proinflammatory cytokine and chemokines.

Vitamin D was found to have major effects on primary human alveolar type II cells in in vitro conditions, and more than 600 genes were activated or inhibited by vitamin $\mathrm{D}$ in these cells (68). Hansdottir et al (69) showed that during a viral infection, inactive vitamin $\mathrm{D}(25(\mathrm{OH}) \mathrm{D})$ can be converted to active vitamin $\mathrm{D}$ $(1,25(\mathrm{OH}) 2 \mathrm{D})$ by the alveolar epithelial cells, and a higher level of expression is observed in host defence gene cathelicidin. This 
finding might indicate that vitamin D might have an organ-specific protective effect in lungs. Vitamin D was also reported to inhibit airway smooth muscle proliferation and to increase surfactant synthesis $(70,71)$. The in vitro study suggested that physiologically relevant doses of vitamin $\mathrm{D}$ had a direct protective effect on alveolar epithelium by stimulating cellular proliferation, wound repair and decreased death of human type 2 alveolar epithelial cells (68).

Miroliaee et al (72) demonstrated that a single high dose vitamin D treatment (300,000 IU) could decrease IL-6 level and reduce the mortality in patients with ventilator-associated pneumonia. Similarly, Lei et al (73) reported that vitamin D3 (300 IU/kg/day) reduced the production of the proinflammatory cytokines (IFN- $\gamma$, TNF- $\alpha$, and IL-6) and inducible nitric oxide synthase (iNOS), increased the production of antimicrobial peptide cathelicidin, elevated the expression of antioxidation level (glutathione reductase and glutamate-cysteine ligase modifier subunit), and increased the autophagy in mice with pneumonia (73). Interestingly, a single high-dose preoperative vitamin D oral administration $(300,000$ IU, a single dose) was reported to prevent an acute respiratory distress syndrome following esophagectomy (74).

Deaths associated with influenza H1N1 pandemics during the 1918-1919 were linked to both secondary bacterial lung infections and to influenza virus itself. As in influenza pandemics, it is known that large proportion of deaths with COVID-19 occur two weeks after the onset of the symptoms. Strong correlations were found between UVB doses in July and pneumonia outcome $(-0.77, \mathrm{p}=$ $0.005)$ or fatality $(r=-0.72, p=0.009)$ rates of the cases $(75)$. Similar results were obtained with wintertime UVB doses. A pneumonia rate of $9.3 \%$ and fatality rate of $3.14 \%$ were observed with influenza, when the UVB dose was $4.7 \mathrm{kl} / \mathrm{m}^{2}$, which were 4.5 and $0.78 \%$, respectively, when the UVB dose reached $8.2 \mathrm{kl} / \mathrm{m}^{2}(75)$. It is well known that vitamin $\mathrm{D}$ level increases depending upon ultraviolet doses. Vitamin D was reported to upregulate increased antiendotoxin, to increase antimicrobial activities and to reduce the production of the proinflammatory cytokines, consequently, it could reduce pneumonia and mortality rates in influenza patients (75). Similarly, vitamin D prevents the lung against COVID-19 infection through reducing the production of the proinflammatory cytokines and increasing antimicrobial peptide cathelicidins.

\section{Vitamin D and cardiovascular diseases}

According to current literature, at least $8.0 \%$ of COVID-19 patients suffer from an acute heart damage (12). Chen et al (11) examined 99 COVID cases and found that $40 \%$ of the patients had cardiocerebrovascular disease history. At least $8.0 \%$ of COVID-19 patients were reported to have an acute heart damage with a strong association with mortality (12). It was even suggested that inflammation could be a potential cause of myocardial damage (76).

Cytokine accumulation directly affects vascular endothelial function and myocardial contractility. IL- 6 and TNF- $\alpha$ can decrease myocyte contractility precisely through the reduction of the systolic calcium level. The experimental study with myocardial ischemia-reperfusion model in rats showed that vitamin D (500 IU/5 day) alleviated myocardial injury considerably with reduced
ST segment and inflammatory cytokine (IL-6), IL-1 $\beta$, TNF- $\alpha$ ) levels (77). In another rat study, vitamin D prevented myocardial infarction by decreasing TNF- $\alpha$ and IL-6 level in isoprenalineinduced myocardial infarction (78). We demonstrated that vitamin $\mathrm{D}$ treatment (60.000/single doses) reduced myocardial damage in cardiotoxicity model in rats $(79,80)$. Vitamin D treatment $(4,000$ IU/for 5 days) was also shown to reduce serum IL-6 and IL-8 levels in patients with acute myocardial infarction (81).

The meta-analysis demonstrated that vitamin D supplement reduced the concentrations of TNF- $\alpha$ in patients with heart failure (82). Vitamin D supplement (2,000 IU oral, daily for nine months) reduced TNF- $\alpha$, and increased IL-10 in adult patients with congestive heart failure (47). Reductions in IL-10, IL-6 and TNF- $\alpha$ levels were also reported for vitamin D supplement (1,000 IU oral, daily for three months) in infant patients with congestive heart failure (83). Reduction IL-6, TNF- $\alpha$ and eleviated IL-10 levels were also reported for vitamin D supplement (1,000 IU oral, daily for three months) in infant patients with congestive heart failure (83). Witte (84) found that vitamin D supplement (4000 IU oral, daily for 12 months) has beneficial effects on o left ventricular structure and function in older patients with a chronic heart failure. levels and reduced risk of coronary heart disease mediated by decreased IL-6, C-reactive protein, interferon- $\gamma$-inducible protein-10 and soluble intercellular adhesion molecule-1 levels (85). In individuals with any cardiovascular disease, it was shown that the increase in cytokines played a significant role in the pathogenesis and that proinflammatory cytokines could be reduced by vitamin D supplementation. Consequently, vitamin D supplementation administered in different doses was found effective especially in high doses in reducing the release of proinflammatory cytokines at all ages. It is known that the mortality rate is high in patients with a cardiovascular disease, when they contract COVID-19 infection. Vitamin D supplementation could reduce the mortality rate in cardiovascular patients infected with COVID-19 through preventing the inflammation.

\section{Vitamin D and kidney diseases}

Following the inflammation, an increased incidence of acute renal injury was reported in patients with COVID-19 $(34,86,87)$. Also, compared to other patients, Cheng et al (86) demonstrated that patients with an acute renal injury had a higher mortality rate. In the meta-analysis, severe COVID-19 infection was suggested to be associated with a chronic kidney disease (CKD) (88). Thus, CKD patients were recommended to be extremely careful against COVID-19 infection.

In chronic kidney disease, active vitamin D level was reported to be associated with a decreased mortality (89). In CKD, 1-hydroxylated vitamin D analogues were found effective for secondary hyperparathyroidism treatment (90). In vitamin D-deficient diabetic patients with the comorbid chronic kidney disease, vitamin D administrations of 1,000 or 2,000 IU/day were reported to safely increase serum 25(OH)D concentrations (91). However, significant improvements were observed for lipid profiles in higher vitamin D dose. Higher dietary vitamin D3 content was reported 


\section{0-877}

to improve immune function in yellow catfish through downregulation of IFN- $\beta$ and pro-inflammatory factors TNF- $\alpha$, IL1- $\beta$, IL-6, IL-8 and up-regulation of anti-inflammatory factor IL-10 (92). Brito et al (93) reported that vitamin D could have protective effects against inflammation at least mediated by monocytes. They also revealed that cathelicidin was associated with the IL-6 and TNF- $\alpha$ levels, which lent further support for this hypothesis (93). Vitamin D supplementation was reported to lower fasting blood sugar, insulin, TNF- $\alpha$ and IL-6 levels (94). Lower TNF- $\alpha$ and malondialdehyde levels after vitamin $\mathrm{D}$ treatment were also reported by Shamardl et al (95).

Vitamin D was reported to protect against drug-induced kidney and liver injury (96). Similarly, BaSalamah et al (97) reported that vitamin $\mathrm{D}$ alleviated kidney inflammation and protected kidney. Accordingly, it could be stated that vitamin D supplement could ease cytokine storm caused by COVID-19 and lower mortality in COVID-19 patients with renal disease.

Abundant expression of ACE2 protein in many cell types was reported to be linked with a high probability of kidney damage (98). Increased ACE2 expression was documented in kidney damage and experimental diabetes models $(99,100)$. Vitamin D treatment was shown to inhibit ACE2 expression (101). Thus, vitamin D supplement could lower ACE2 expression in kidney, preventing COVID-19 entry into kidneys and protecting against possible damage in kidney.

\section{Appropriate vitamin D doses}

Despite the lack of a specific guideline from endocrinology or vitamin D societies, vitamin D concentrations of above $30 \mu \mathrm{g} / \mathrm{L}$ (75 $\mathrm{nmol} / \mathrm{L}$ ) are recommended in many studies (102). Misra et al (103) recommended a daily dose of $400 \mathrm{IU}$ for adolescents and children. Daily vitamin D supplements ranging from 200 IU to 600 IU were suggested by The Institute of Medicine (104) for adults to sustain enough vitamin D levels in the body. In vitamin D deficiency situation, however, much higher supplementation rates of 28,000 IU weekly or 50,000 IU monthly are recommended depending on the severity of the deficiency (105). No toxicity was observed in patients supplemented with vitamin D doses as high as 10,000 IU of vitamin D3 administered daily for five months (106). Differences were reported between the countries for vitamin D recommendations and their implementation to achieve the adequate vitamin D levels (107). A daily dose of up to 2,000 IU a day was suggested to maintain an adequate level of 25-hydroxyvitamin D (25OHD) (108). Chang and Lee (24) stated that people could take 2000 IU per day for 6 to 12 weeks after the first year of life, and a daily dose of 600 to 1000 IU is appropriate to maintain adequate vitamin D supply. However, for high-risk groups, this daily allowance could be as high as 6000 IU. In another study, Shirvani et al (109) mentioned that $10,000 \mathrm{IU}$ daily vitamin D supplementation for six months was safe and regulated parathyroid hormone (PTH) levels. They also mentioned that this supplement regime had a considerable effect on the expression of 1200 genes and on metabolic patterns. Thus, considering the results of literature, it is seen that the safe dose range of vitamin $\mathrm{D}$ is high. Due to that fact it may be beneficial to administer high doses of the vitamin $\mathrm{D}$ in patients with Covid 19. However, specific vitamin D supplementation recommendations should be applied for each patient individually.

\section{Conclusion}

COVID-19 is viral agent with a very high contagion and causes mainly pneumonia. Development of the effective prevention and treatment methods for COVID-19 is an urgent need. Vitamin D is an immunomodulator hormone with a high safety profile whose anti-inflammatory, antimicrobial and antioxidant effects were proven in many studies. Vitamin D supplement could provide a protective effect against the infection of COVID-19 virus. It could be used as an agent to alleviate the inflammation in COVID-19-infected patients and to prevent multiple organ damage due to the virus.

\section{References}

1. WHO. https://www.who.int/docs/default-source/coronaviruse/situationreports/20200229-sitr ep-40-covid-19.pdf?sfvrsn=849d0665_2.

2. Guan WJ, Ni ZY, Hu Y et al. Clinical characteristics of coronavirus disease 2019 in China. N Engl J Med 2020. DOI: 10.1056/NEJMoa2002032.

3. Lai CC, Shih TP, Ko WC et al. Severe acute respiratory syndrome coronavirus 2 (SARS-CoV-2) and coronavirus disease - 2019 (COVID-19): The epidemic and the challenges. Int J Antimicrob Agents 2020: 105924. DOI: $10.1016 /$ j.ijantimicag.2020.105924.

4. Tian, H.Y. 2019-nCoV: new challenges from coronavirus. Zhonghua yu Fang yi xue za zhi [Chin J Prevent Med], 2020; 54: E001-E001.

5. Huang Y, Zhou H, Yang $R$ et al. Clinical characteristics of 36 non-survivors with COVID-19 in Wuhan, China. 2020a; medRxiv 2020.02.27.20029009. https://doi.org/10.1101/2020.02.27.20029009

6. Huang C, Wang Y, Li X et al. Clinical features of patients infected with 2019 novel coronavirus in Wuhan, China. Lancet 2020b; 395: 497-506. https://doi.org/10.1016/S0140-6736 (20)30183-5.

7. Peiris JS, Lai ST, Poon LL et al. Coronavirus as a possible cause of severe acute respiratory syndrome. Lancet 2003; 361 (9366): 1319-1325.

8. Kupferschmidt K. Researchers scramble to understand camel connection to MERS. Science 2013; 341: (6147): 702.

9. Zhu N, Zhang D, Wang $\mathbf{W}$ et al. A Novel Coronavirus from Patients with Pneumonia in China, 2019. N Engl J Med 2020; 382 (8): 727-733.

10. Yao XH, Li TY, He ZC et al. A pathological report of three COVID-19 cases by minimally invasive autopsies. Zhonghua bing li xue za zhi (Chin J Pathol) 2020; 49: E009

11. Chen N, Zhou M, Dong $X$ et al. Epidemiological and clinical characteristics of 99 cases of 2019 novel coronavirus pneumonia in Wuhan, China: a descriptive study. Lancet 2020a.

12. Li B, Yang J, Zhao F et al. Prevalence and impact of cardiovascular metabolic diseases on COVID-19 in China. Clinical Research in Cardiology, 2020: 1-8.

13. Roser M, Ritchie H. Coronavirus Disease (COVID-19). Our World in Data. 2020. https: //ourworldindata. org/coronavirus.

14. Zhang B, Zhou X, Qiu $Y$ et al. Clinical characteristics of 82 death cases with COVID-19. medRxiv 2020a, in press. Available from: https:// doi.org/10.1101/2020.02.26.20028191. 
15. Christakos, S, Ajibade DV, Dhawan P et al. Vitamin D: Metabolism. Rheum Dis Clin N Am 2012; 38: 1-11.

16. Wagner CL, Greer FR. Prevention of rickets and vitamin D deficiency in infants, children, and adolescents. Pediatrics 2008; 122 (5): 1142-1152.

17. Miricescu D, Totan A, Stanescu AMA et al. Vitamin D deficiency and insulin resistance. Pract Med 2019; 14 (67): 227-232.

18. Braun AB, Litonjua AA, Moromizato T et al. Association of low serum 25-hydroxyvitamin D levels and acute kidney injury in the critically ill. Crit Care Med 2012; 40: 3170-3179.

19. Quraishi SA, Litonjua AA, Moromizato T et al. Association between prehospital vitamin D status and hospital-acquired bloodstream infections Am J Clin Nutr 2013; 98: 952-959.

20. Moromizato T, Litonjua AA, Braun AB et al. Association of low serum 25-hydroxyvitamin D levels and sepsis in the critically ill. Crit Care Med 2014; 42: 97-107.

21. Thickett DR, Moromizato T, Litonjua AA et al. Association between prehospital vitamin D status and incident acute respiratory failure in critically ill patients: A retrospective cohort study. BMJ Open Respir Res 2015; 2: e000074.

22. Rai V, Agrawal DK. Role of vitamin D in cardiovascular diseases. Endocrinol Metab Clin 2017; 46 (4): 1039-1059.

23. Kaminska S, Pikala M, Dziankowska-Zaborszczyk E et al. Vitamin $\mathrm{D}$ - dietary intake, supplementation and metabolic status of Polish adults. Int J Occup Med Environ Health. 2020; 33 (1): 107-111.

24. Chang SW, Lee HC. Vitamin D and health - The missing vitamin in humans. Pediatr Neonatol 2019; 60 (3): 237-244.

25. Hu Z, Tao S, Liu H, Pan G, Li B, Zhang Z. The Association between Polymorphisms of Vitamin D Metabolic-Related Genes and Vitamin D3 Supplementation in Type 2 Diabetic Patients. J Diabet Res 2019: 8289741

26. Tipnis SR, Hooper NM, Hyde R et al. A human homolog of angiotensin-converting enzyme. Cloning and functional expression as a captopril-insensitive carboxypeptidase. J Biol Chem 2000; 275: 33238-33243. DOI: $10.1074 /$ jbc.M002615200.

27. Batlle D, Wysocki J, Soler MJ, Ranganath K. Angiotensin-converting enzyme 2: enhancing the degradation of angiotensin II as a potential therapy for diabetic nephropathy. Kidney Int 2012; 81: 520-528. DOI: 10.1038/ki.2011.381.

28. Ferrario CM, Chappell MC, Tallant EA et al. Counterregulatory actions of angiotensin- (1-7). Hypertension. 1997; 30 (3 Pt 2): 535-541. DOI: 10.1161/01.hyp.30.3.535.

29. Zou $\mathbf{X}$ et al. The single-cell RNA-seq data analysis on the receptor ACE2 expression reveals the potential risk of different human organs vulnerable to 2019-nCoV infection. Front Med 2020. DOI: 10.1007/ s11684-020-0754-0.

30. Zhao $\mathbf{Y}$ et al. Single-cell RNA expression profiling of ACE2, the putative receptor of Wuhan 2019-nCov. Preprint at https://www.biorxiv. org/content/10.1101/.

31. Hamming I, Timens W, Bulthuis MLC et al. Tissue distribution of ACE2 protein, the functional receptor for SARS coronavirus. A first step in understanding SARS pathogenesis. J Pathol 2004; 203 (2): 631-637.

32. Zhang, H. et al. The digestive system is a potential route of 2019-nCov infection: a bioinformatics analysis based on single-cell transcriptomes. https://www.biorxiv.org/content/10.1101/2020.01.30.927806v1 (2020b).
33. Chai $\mathrm{X}$ et al. Specific ACE2 expression in cholangiocytes may cause liver damage after 2019-nCoV infection. Preprint at https://www.biorxiv. org/content/10.1101/ 2020.02.03.931766v1 (2020).

34. Xu H, Zhong $\mathbf{L}$, Deng $\mathbf{J}$ et al. High expression of ACE2 receptor of 2019-nCoV on the epithelial cells of oral mucosa. Internat J Oral Sci 2020; 12 (1): $1-5$.

35. Hashimoto T, Perlot T, Rehman A et al. ACE2 links amino acid malnutrition to microbial ecology and intestinal inflammation. Nature 2012; 487 (7408): 477-481.

36. Wu A, Peng Y, Huang B et al. Genome composition and divergence of the novel coronavirus (2019-nCoV) originating in China. Cell Host Microbe. 2020; 27 (3): 325.

37. Zheng YY, Ma YT, Zhang JY, Xie X. COVID-19 and the cardiovascular system. Nat Rev Cardiol 2020.

38. Conti P, Ronconi G, Caraffa A et al. Induction of pro-inflammatory cytokines (IL-1 and IL-6) and lung inflammation by Coronavirus-19 (COVID-19 or SARS-CoV-2): anti-inflammatory strategies. J Biol Regul Homeost Agents 2020; 34. DOI: 10.23812/CONTI-E.

39. Chen C, Zhang XR, Ju ZY, He WF. Advances in the research of cytokine storm mechanism induced by Corona Virus Disease 2019 and the corresponding immunotherapies. Zhonghua Shaoshang Zazhi 2020b; $36(0): 69$.

40. Liu Y, Zhang C, Huang F et al. 2019-novel coronavirus (2019-nCoV) infections trigger an exaggerated cytokine response aggravating lung injury. 2020. http://www.chinaxiv.org/abs/202 002.00018.

41. Wu D, Yang XO. TH17 Responses in Cytokine Storm of COVID-19: An Emerging Target of JAK2 Inhibitor Fedratinib. J Microbiol Immunol Infect 2020.

42. Golden EB, Cho HY, Hofman FM et al. Quinoline-based antimalarial drugs: a novel class of autophagy inhibitors. Neurosurg Focus 2015; 38 (3): E12.

43. Aguiar ACC, Murce E, Cortopassi WA et al. Chloroquine analogs as antimalarial candidates with potent in vitro and in vivo activity. Int $\mathbf{J}$ Parasitol Drugs Drug Resist 2018; 8 (3): 459-464.

44. Wang M, Cao R, Zhang $L$ et al. Remdesivir and chloroquine effectively inhibit the recently emerged novel coronavirus $(2019-\mathrm{nCoV})$ in vitro Cell Res (2020): 1-3, 10.1038/s41422-020-0282-0.

45. Khoo AL et al. Translating the role of vitamin D3 in infectious diseases. Crit Rev Microbiol 2012; 38 (2): 122-135.

46. Cantorna MT, Mahon BD. D-hormone and the immune system. J Rheumatol Suppl 2005; 76: 11-20.

47. Schleithoff SS, Zittermann A, Tenderich G et al. Vitamin D supplementation improves cytokine profiles in patients with congestive heart failure: a double-blind, randomized, placebo-controlled trial. Am J Clin Nutr 2006; 83: 754-759.

48. Ardizzone S, Cassinotti A, Trabattoni D et al. Immunomodulatory effects of 1,25-dihydroxyvitamin D3 on TH1/TH2 cytokines in inflammatory bowel disease: an in vitro study. Int J Immunopathol Pharmacol 2009; 22: 63-71.

49. Chastre J, Fagon JY. Ventilator-associated pneumonia. Amer J Respir Crit Care Med 2002; 165 (7): 867-903.

50. Society AT, I.D.S.o. America. Guidelines for the management of adults with hospital-acquired, ventilator-associated, and healthcare-associated pneumonia. Am J Respir Crit Care Med 2005; 171: 388-416. 
870-877

51. Palmer MT, Lee YK, Maynard CL et al. Lineage-specific effects of 1,25-dihydroxyvitamin d (3) on the development of effector cd $4 \mathrm{t}$ cells. J Biol Chem 2011; 286: 997-1004.

52. Peterson CA, Heffernan ME. Serum tumor necrosis factor-alpha concentrations are negatively correlated with serum $25(\mathrm{OH}) \mathrm{D}$ concentrations in healthy women. J Inflamm (Lond) 2008; 5: 10.

53. Talmor Y, Bernheim J, Klein $\mathbf{O}$ et al. Calcitriol blunts pro-atherosclerotic parameters through NFkappaB and p38 in vitro. Eur J Clin Invest 2008; 38: 548-554.

54. Provvedini DM, Tsoukas CD, Deftos LJ, Manolagas SC. 1,25-dihydroxyvitamin d3 receptors in human leukocytes. Science 1983; 221: 1181-1183.

55. Tsoukas CD, Provvedini DM, Manolagas SC. 1,25-dihydroxyvitamin d3: A novel immunoregulatory hormone. Science 1984; 224: 1438-1440.

56. Ballermann BJ, Zeidel ML, Gunning ME, Brenner BM. Vasoactive peptides and the kidney. In: Brenner BM, Rector FC (Ed)s. The kidney. Philadelphia: W.B. Saunders Company, 1991: 510-583.

57. Li W, Moore MJ, Vasilieva N et al. Angiotensin-converting enzyme 2 is a functional receptor for the SARS coronavirus. Nature 2003; 426: $450-454$.

58. Kuba K, Imai Y, Rao $\mathbf{S}$ et al. A crucial role of angiotensin converting enzyme 2 (ACE2) in SARS coronavirus-induced lung injury. Nat Med 2005; 11: 875-879.

59. Imai Y, Kuba K, Penninger JM. Angiotensin-converting enzyme 2 in acute respiratory distress syndrome. Cell Mol Life Sci 2007; 64 (15): 2006-2012.

60. Sparks MAet al. Classical rennin-angiotensin system in kidney physiology. Compr Physiol 2014; 4: 1201-1228.

61. Hanff TC, Harhay MO, Brown TS et al. Is There an Association Between COVID-19 Mortality and the Renin-Angiotensin System - a Call for Epidemiologic Investigations. Clin Infect Dis 2020: pii: ciaa329.

62. Kiely DG, Cargill RI,Wheeldon NM et al. Haemodynamic and endocrine effects of type 1 angiotensin II receptor blockade in patients with hypoxaemic cor pulmonale. Cardiovasc Res 1997; 33: 201-208.

63. Li YC, Qiao G, Uskokovic M et al. Vitamin D: a negative endocrine regulator of the renin-angiotensin system and blood pressure. J Steroid Biochem Mol Biol 2004; 89: 387-392.

64. Rammos G, Tseke P, Ziakka $S$. Vitamin D, the renin-angiotensin system, and insulin resistance. Internat Urol Nephrol 2008; 40 (2): 419-426.

65. Varakantham V, Ale K, Sailoo AKK et al. Sex-specific role of CYP24A1 rs2762939 in the risk of essential hypertension based on the serum vitamin D and total renin concentrations. Genomics 2020; 112 (1): $764-768$.

66. Zhang Z, Zhang Y, Ning G et al. Combination therapy with AT1 blocker and vitamin D analog markedly ameliorates diabetic nephropathy: blockade of compensatory renin increase. Proc Nat Acad Sci 2008; 105 (41): 15896-15901.

67. Xu J, Yang J, Chen J et al. Vitamin D alleviates lipopolysaccharideinduced acute lung injury via regulation of the renin-angiotensin system. Mol Med Reports 2017; 16 (5): 7432-7438.

68. Dancer RC, Parekh D, Lax S et al. Vitamin D deficiency contributes directly to the acute respiratory distress syndrome (ARDS). Thorax 2015; 70: 617-624.
69. Hansdottir S, Monick MM, Hinde SL et al. Respiratory epithelial cells convert inactive vitamin D to its active form: Potential effects on host defense. J Immunol 2008; 181: 7090-7099.

70. Nguyen M, Trubert CL, Rizk-Rabin M et al. 1,25-Dihydroxyvitamin D3 and fetal lung maturation: immunogold detection of VDR expression in pneumocytes type II cells and effect on fructose 1,6 bisphosphatase. J Steroid Biochem Mol Biol 2004; 89-90 (1-5): 93-97.

71. Damera G, Fogle HW, Lim P et al. Vitamin D inhibits growth of human airway smooth muscle cells through growth factor-induced phosphorylation of retinoblastoma protein and checkpoint kinase 1. Br J Pharmacol 2009; 158 (6): 1429-1441.

72. Miroliaee AE, Salamzadeh J, Shokouhi S et al. The study of vitamin $\mathrm{D}$ administration effect on CRP and Interleukin- 6 as prognostic biomarkers of ventilator associated pneumonia. J Crit Care 2018; 44: 300-305.

73. Lei GS, Zhang C, Cheng BH et al. Mechanisms of action of vitamin D as supplemental therapy for Pneumocystis pneumonia. Antimicrob Agents Chemother 2017; 61 (10): e01226-17.

74. Parekh D, Dancer RC, Scott A et al. Vitamin D to prevent lung injury following esophagectomy-a randomized, placebo-controlled trial. Crit Care Med 2018; 46 (12): e1128.

75. Grant WB, Giovannucci E. The possible roles of solar ultraviolet-B radiation and vitamin $\mathrm{D}$ in reducing case-fatality rates from the 1918-1919 influenza pandemic in the United States. Dermato-Endocrinology 2009; 1 (4): 215-219.

76. Guo YR, Cao QD, Hong ZS et al. The origin, transmission and clinical therapies on coronavirus disease 2019 (COVID-19) outbreak - an update on the status. Militar Med Res 2020; 7 (1): 1-10.

77. Qian X, Zhu M, Qian W, Song J. Vitamin D attenuates myocardial ischemia-reperfusion injury by inhibiting inflammation via suppressing the RhoA/ROCK/NF-KB pathway. Biotechnol Appl Biochem 2019; 66 (5): $850-857$.

78. El-Gohary OA, Allam MM. Effect of vitamin D on isoprenaline-induced myocardial infarction in rats: possible role of peroxisome proliferator-activated receptor- $\gamma$. Canad J Physiol Pharmacol 2017; 95 (6): 641-646.

79. Aygun H, Basol N, Gul SS. Cardioprotective Effect of Paricalcitol on Amitriptyline-induced Cardiotoxicity in Rats: Comparison of [99m Tc] PYP Cardiac Scintigraphy with Electrocardiographic and Biochemical Findings. Cardiovasc Toxicol 2020: 1-10.

80. Gül SS, Aygün H. Cardioprotective effect of vitamin D and melatonin on doxorubicin-induced cardiotoxicity in rat model: an electrocardiographic, scintigraphic and biochemical study. Eur Res J 2019; 5 (4): 649-657.

81. Arnson Y, Itzhaky D, Mosseri M et al. Vitamin D inflammatory cytokines and coronary events: a comprehensive review. Clin Rev Allergy Immunol 2013; 45 (2): 236-247.

82. Rodriguez AJ, Mousa A, Ebeling PR et al. Effects of vitamin D supplementation on inflammatory markers in heart failure: a systematic review and meta-analysis of randomized controlled trials. Sci Reports 2018; 8 (1): 1-8.

83. Shedeed SA. Vitamin D supplementation in infants with chronic congestive heart failure. Pediatr Cardiol 2012; 33: 713-719. https://DOI. org/10.1007/s00246-012-0199-6.

84. Witte KK, Byrom R, Gierula J, Paton MF, Jamil HA, Lowry JE ... Greenwood JP. Effects of vitamin D on cardiac function in patients with chronic HF: the VINDICATE study. J Amer Coll Cardiol 2016; 67(22): 2593-2603. 
85. Karakas M, Thorand B, Zierer A et al. Low levels of serum 25-hydroxyvitamin D are associated with increased risk of myocardial infarction, especially in women: results from the MONICA/KORA Augsburg case cohort study. J Clin Endocrinol Metab 2013; 98 (1): 272-280.

86. Cheng Y, Luo R, Wang $K$ et al. Kidney impairment is associated with in-hospital death of COVID-19 patients. medRxiv. 2020.

87. Rismanbaf A, Zarei S. Liver and Kidney Injuries in COVID-19 and Their Effects on Drug Therapy; a Letter to Editor. Arch Acad Emerg Med 2020; 8 (1): e17.

88. Henry BM, Lippi G. Chronic kidney disease is associated with severe coronavirus disease 2019 (COVID-19) infection. Int Urol Nephrol 2020. DOI: $10.1007 / \mathrm{s} 11255-020-02451-9$.

89. Bover J, Egido J, Fernández-Giráldez E et al. Vitamin D, vitamin $\mathrm{D}$ receptor and the importance of its activation in patients with chronic kidney disease. Nefrologia 2015; 35 (1): 28-41.

90. Zand L, Kumar R. The Use of Vitamin D Metabolites and Analogues in the Treatment of Chronic Kidney Disease. Endocrinol Metab Clin North Am 2017; 46 (4): 983-1007.

91. Kim J, Nam JS, Kim H, Lee HS, Lee JE. No effect of vitamin D supplementation on metabolic parameters but on lipids in patients with type 2 diabetes and chronic kidney disease. Int J Vitam Nutr Res 2020: 1-10.

92. Cheng K, Tang Q, Huang $\mathbf{Y}$ et al. Effect of vitamin D3 on the immunomodulation of head kidney after Edwardsiella ictaluri challenge in yellow catfish (Pelteobagrus fulvidraco). Fish Shellfish Immunol 2020; 99: 353-361.

93. Brito RBO, Rebello JF, Grabulosa CC et al. 25-vitamin D reduces inflammation in uremic environment. Sci Rep 2020; 10 (1): 128.

94. Esfandiari A, Pourghassem Gargari B, Noshad H et al. The effects of vitamin D3 supplementation on some metabolic and inflammatory markers in diabetic nephropathy patients with marginal status of vitamin D: A randomized double blind placebo controlled clinical trial. Diabetes Metab Syndr 2019; 13 (1): 278-283.

95. Shamardl HA, El-Ashmony SM, Kamel HF, Fatani SH. Potential Cardiovascular and Renal Protective Effects of Vitamin D and Coenzyme Q10 in 1-NAME-induced Hypertensive Rats. Am J Med Sci 2017; 354 (2): 190-198.

96. Abo El-Magd NF, Eraky SM. The molecular mechanism underlining the preventive effect of vitamin D against hepatic and renal acute toxicity through the NrF2/ BACH1/ HO-1 pathway. Life Sci 2020; 244 : 117331.
97. BaSalamah MA, Abdelghany AH, El-Boshy M et al. Vitamin D alleviates lead induced renal and testicular injuries by immunomodulatory and antioxidant mechanisms in rats. Sci Rep 2018; 8 (1): 4853.

98. Deng YY, Zheng Y, Cai GY et al. Single-cell RNA sequencing data suggest a role for angiotensin-converting enzyme 2 in kidney impairment in patients infected with 2019-nCoV. Chin Med J 2020.

99. Ye M, Wysocki J, Naaz P et al. Increased ACE 2 and decreased ACE protein in renal tubules from diabetic mice: a renoprotective combination? Hypertension 2004; 43: 1120-1125.

100. Lely AT, Hamming I, van Goor H, Navis GJ. Renal ACE2 expression in human kidney disease. J Pathol 2004; 204: 587-593.

101. Ali RM, Al-Shorbagy MY, Helmy MW, El-Abhar HS. Role of Wnt4/ $\beta$-catenin, Ang II/TGF $\beta$, ACE2, NF- $\mathrm{BB}$, and IL-18 in attenuating renal ischemia/reperfusion-induced injury in rats treated with Vit $\mathrm{D}$ and pioglitazone. Eur J Pharmacol 2018; 831: 68-76.

102. Vieth R, Bischoff-Ferrari H, Boucher BJ et al. The urgent need to recommend an intake of vitamin D that is effective. Am J Clin Nutr 2007; 85: 649-650.

103. Misra M, Pacaud D, Petryk A, Collett-Solberg PF, Kappy M, Drug and Therapeutics Committee of the Lawson Wilkins Pediatric Endocrine Society. Vitamin D deficiency in children and its management: review of current knowledge and recommendations. Pediatrics 2008; 122 (2): $398-417$.

104. Institute of Medicine. Dietary reference intakes for calcium, phosphorus, magnesium, vitamin D, and fluoride. Washington, DC: Insitute of Medicine, 1999.

105. Dawson-Hughes B, Heaney RP, Holick MF et al. Estimates of optimal vitamin D status. Osteoporos Int 2005; 16: 713-716.

106. Holick MF. Vitamin D deficiency. N Engl J Med 2007; 357: 266-281.

107. Itkonen ST, Andersen R, Björk AK et al. Vitamin D status and current policies to achieve adequate vitamin D intake in the Nordic countries. Scand J Public Health 2020:1403494819896878. DOI: 10.1177/1403494819896878.

108. Kojecký V, Matouš J, Zádorová Z et al. Vitamin D supplementation dose needs to be higher in patients with inflammatory bowel disease: interventional study. Vnitr Lek 2019; 65 (7-8): 470-474.

109. Shirvani A, Kalajian TA, Song A et al. Variable Genomic and Metabolomic Responses to Varying Doses of Vitamin D Supplementation. Anticancer Res 2020; 40 (1): 535-543. 